\title{
Short Segment versus Long Segment Pedicle Screws Fixation in Management of Thoracolumbar Burst Fractures: Meta-Analysis
}

\author{
Tarek Ahmed Aly \\ Department of Orthopedic Surgery, Tanta University School of Medicine, Tanta, Egypt
}

\begin{abstract}
Posterior pedicle screw fixation has become a popular method for treating thoracolumbar burst fractures. However, it remains unclear whether additional fixation of more segments could improve clinical and radiological outcomes. This meta-analysis was performed to evaluate the effectiveness of fixation levels with pedicle screw fixation for thoracolumbar burst fractures. MEDLINE, EMBASE, the Cochrane Central Register of Controlled Trials, Springer, and Google Scholar were searched for relevant randomized and quasirandomized controlled trials that compared the clinical and radiological efficacy of short versus long segment for thoracolumbar burst fractures managed by posterior pedicle screw fixation. Risk of bias in included studies was assessed using the Cochrane Risk of Bias tool. Based on predefined inclusion criteria, Nine eligible trials with a total of 365 patients were included in this meta-analysis. Results were expressed as risk difference for dichotomous outcomes and standard mean difference for continuous outcomes with $95 \%$ confidence interval. Baseline characteristics were similar between the short and long segment fixation groups. No significant difference was identified between the two groups regarding radiological outcome, functional outcome, neurologic improvement, and implant failure rate. The results of this meta-analysis suggested that extension of fixation was not necessary when thoracolumbar burst fracture was treated by posterior pedicle screw fixation. More randomized controlled trials with high quality are still needed in the future.
\end{abstract}

Keywords: Thoracolumbar; Spine; Burst; Short-segment; Long-segment; Pedicle screws; Fixation

\section{Introduction}

Thoracolumbar vertebral body fractures are common spinal injuries, and fractures of burst type account for $21 \%$ to $58 \%$ of all thoracolumbar spinal fractures. Thoracolumbar burst fractures, frequently associated with kyphotic deformity and neurological deficit, are very common in younger patients and could have a great impact on their daily physical activities. However, there is still controversy regarding the ideal management for these injuries [1-3].

Treatment goals for thoracolumbar burst fractures include restoration of spinal stability and alignment, correction of kyphotic deformity and decompression of the spinal canal. For achievement of these desired results, most authors believe that burst fractures require surgical intervention; however, controversy with regard to treatment continues [4-6].

Various surgical techniques, including posterior short

Received May 17, 2016; Revised Jun 19, 2016; Accepted Jul 5, 2016

Corresponding author: Tarek Ahmed Aly

Department of Orthopedic Surgery, Tanta University School of Medicine, 48th, Sarwat street, Tanta 31111, Egypt

Tel: +20-40-3303060, Fax: +20-40-3347744, E-mail: elphara3on@hotmail.com 
segment or long segment pedicle screw fixation, direct anterior decompression through corpectomy, and combined methods through anterior and posterior spinal approaches, have since arisen for treatment of thoracolumbar burst fractures [7-9].

However, the decision of surgical methods still remains controversy $[10,11]$.

Also, the ideal treatment for thoracolumbar burst fractures is controversial regarding the use of short or long posterior fixation constructs [12-15].

Long posterior fixation with pedicle screws and rods two-levels above and below the fracture level provide better fixation; however, it results in potentially extraneous instrumentation and increased load on the lower discs [16].

On the other hand, short posterior fixation using pedicle screws with interconnected rods one-level above and below the fracture level not only limits the number of fused segments, but also prevents excessive loads on the adjacent discs. However, reports on the use of short posterior fixation for burst fractures describe high rates of failure in fixation and kyphotic collapse $[17,18]$.

Several trials have been conducted comparing the clinical and radiological efficacy of posterior short segment fixation versus posterior long segment fixation $[9,13,19$ 23]. The objective of this meta-analysis was to identify and summarize the evidence from randomized controlled trials on the effectiveness of number of fixed spine segments for thoracolumbar burst fractures.

\section{Materials and Methods}

\section{Search strategy}

Electronic searches of MEDLINE, EMBASE, the Cochrane Central Register of Controlled Trials and other internet databases were performed to identify trials according to the Cochrane Collaboration guidelines [24]. We screened the title and abstract by combining the term "([ short $^{*} \mathrm{OR}$ long* ${ }^{\star}$ AND segment ${ }^{*}$ ) AND ([fixation] OR "Fracture Fixation"[Mesh]) AND (burst AND fracture* AND thoracolumbar) OR ("Thoracic Vertebrae"[Mesh] OR "Lumbar Vertebrae"[Mesh]) AND "Spinal Fractures"[Mesh])."

There was no language restriction. A comprehensive search of reference lists of published articles was also performed to ensure inclusion of all possible studies. Unpublished data were not reviewed.

\section{Selection criteria}

Trials with the following characteristics were included: (1) randomized, quasi-randomized or controlled clinical trials, (2) patients without confirmed pathological thoracolumbar burst fractures based on computed tomography and plain radiographs, (3) adult patients ( $\geq 18$ years), (4) comparison of the short segment fixation and long segment fixation of surgical management, (5) Over 24-month follow-up, and (6) full-text articles.

We excluded articles that were duplicate reports of earlier trials or post hoc analyses of randomized controlled trial data and articles whose full text we were unable to acquire.

\section{Data extraction}

Data were collected based on following categories where available. (1) Basic characteristics, including study design, inclusion/exclusion criteria, age, sex, enrolled number, and follow-up rate. (2) Injury information, consisting of classification and location of fracture, neurological status, preoperative spinal canal compromise, preoperative kyphotic angle, preoperative decreased vertebral body height. (3) Surgical information, such as fixed levels (short or long segment fixation), type of internal fixation and spinal canal decompression information. (4) Primary outcomes, including correction of kyphotic angle and sagittal index, functional outcome, and implant failure as a complication.

\section{Statistical analysis}

Both baseline characteristics and surgical outcomes were pooled and analyzed. Meta-analysis was performed using Review Manager ver. 5.3 software (Cochrane Collaboration, Oxford, UK). Risk ratios were calculated for binary outcomes and standard weighted mean differences for continuous outcomes, along with $95 \%$ confidence intervals (CI). The level of significance was set at $p=0.05$. Heterogeneity was evaluated using the $\chi^{2}$ test and $\mathrm{I}^{2}$ statistics (considered significant when $p$-value for $\chi^{2}$ test, 0.10 or $\left.I^{2}>50 \%\right)$. Fixed-effect models were applied unless statistical heterogeneity was significant, in which case randomeffect models were used. Through subgroup analysis, we investigated the influence of study design and fixed levels (short or long segment fixation) on pooled estimates. 


\section{Results}

\section{Study characteristics}

The search strategy identified 217 potential studies from the databases. 208 papers were excluded according to our inclusion criteria. No additional studies were obtained after reference review. Finally, nine trials including were selected and analyzed [9,13,19-23,25] (Fig. 1).

These studies involved 365 patients, 201 patients in the short segment group and 164 patients in the long segment group (Fig. 2). The majority of the included trials were small studies with between 12 and 69 participants. The patients' characteristics were comparable within each study group. Individual patient data were available from these articles. This did not include data for those lost to followup. There were no between-group differences in gender, mechanism of injury, level of fracture or length of followup.

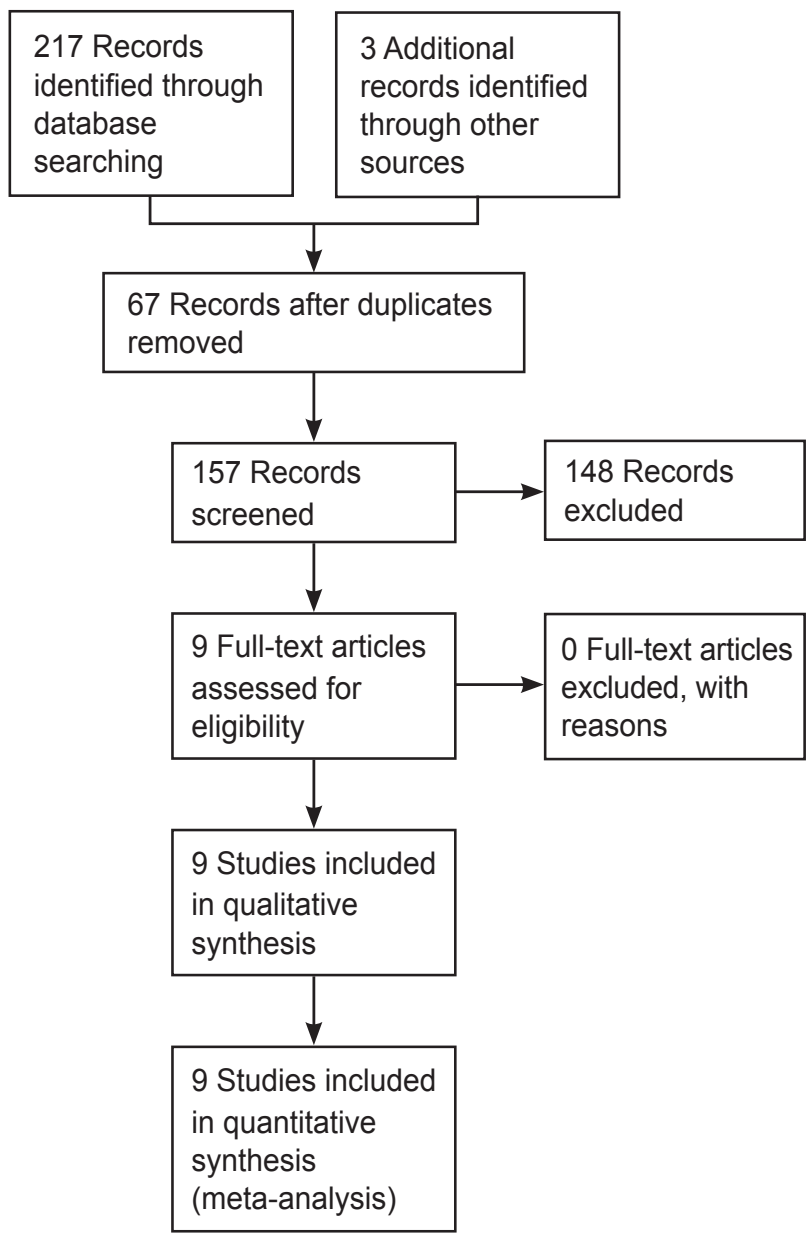

Fig. 1. Flow diagram of the study selection.

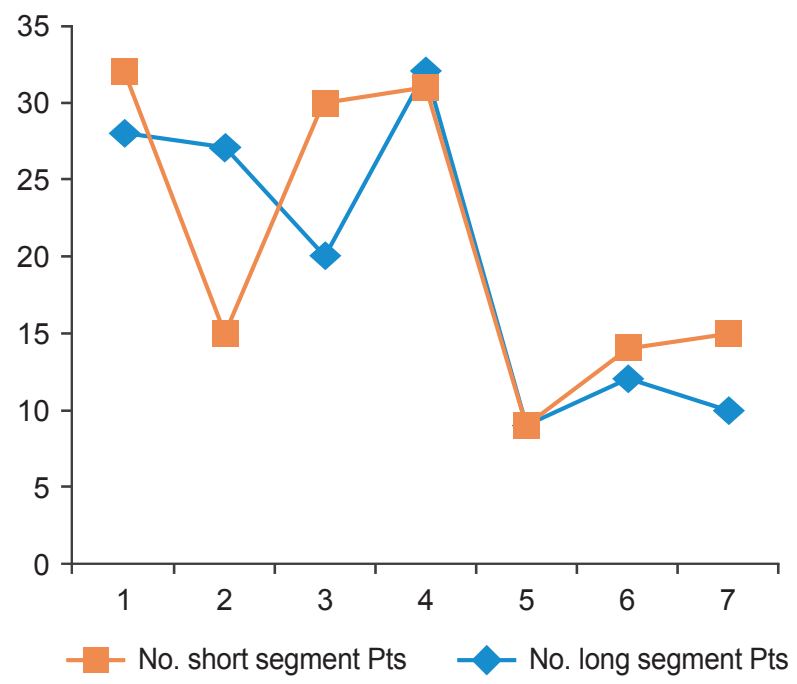

Fig. 2. Number of patients in both groups. Pts, patients.

\section{Results of data analysis}

1) Radiographic outcomes

(1) Anterior vertebral height

Data regarding anterior vertebral height were available in all studies with a total of 365 patients. The fixed-effects model was applied to determine the preoperative anterior vertebral height between the two groups (heterogeneity: $\left.\mathrm{I}^{2}=92 \%\right)$. The pooled risk difference was -0.05 ( $95 \%$ confidence interval [CI], -0.19 to 0.30 ; $p<0.67$ ) for patients in the short segment group compared to the long segment group, suggesting that there was no significant difference between these two treatment groups in terms of anterior vertebral height (Fig. 3).

(2) The Cobb angle

The Cobb angle was reported in all studies except one [25]: those studies reported postoperative Cobb's angle (short segment group, 195; long segment group, 158). Pooled data of the random-effects model from the relevant studies revealed no significant difference (CHI 96.76, $p=0.67$ $>0.05)$ and significant heterogeneity: $\mathrm{I}^{2}=92 \%$. However, no between-group difference was found in the Cobb angle $(p<0.00001)$. The pooled standard mean difference was -0.04 (95\% CI, -0.26 to $0.18 ; p>0.01)$ for patients in the short segment fixation compared to the long segment fixation group, suggesting that there was no significant difference between these two treatment groups postoperative Cobb's angle correction (Fig. 4).

Six studies reported the final follow-up Cobb's angle 
in 154 patients (short segment group, 118; long segment group, 75) [1,20-23,25]. The fixed-effects model was applied to compare the follow up Cobb's angle between the two groups. Pooled data from the relevant studies revealed a significant difference (MD, 1.19; 95\% CI, 0.66 to 2.14; $p<0.00001$ ) with heterogeneity: $\mathrm{I}^{2}=90 \%$ (Figs. 5, 6).

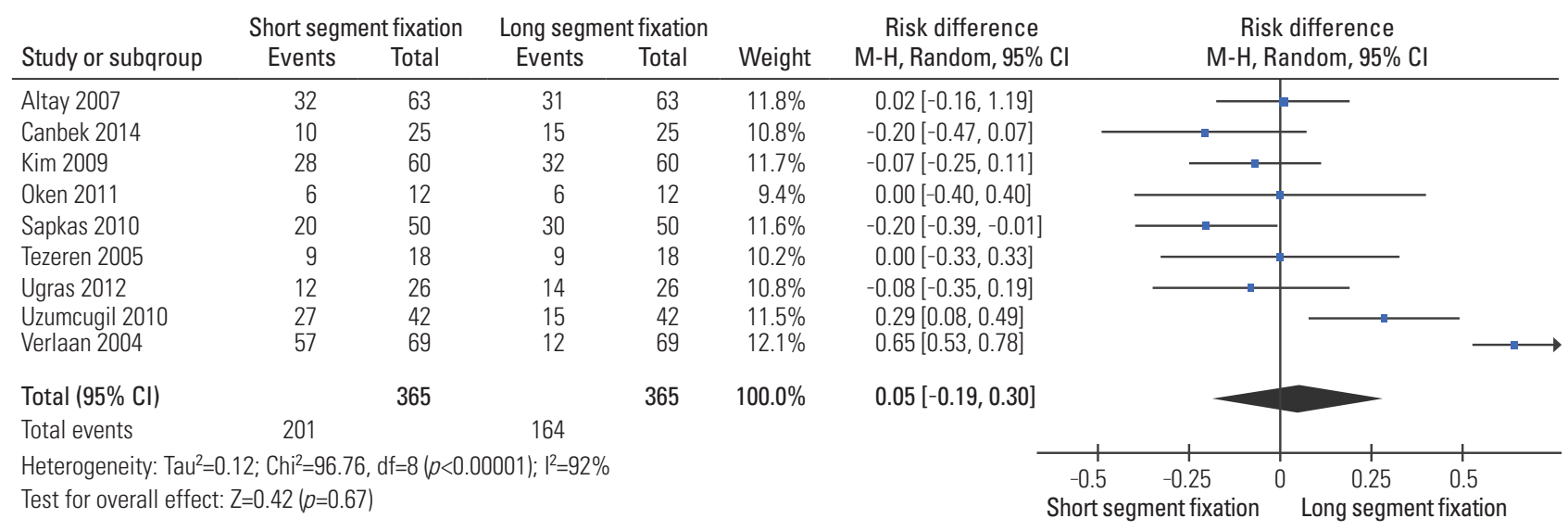

Fig. 3. Risk difference estimate for anterior vertebral height.

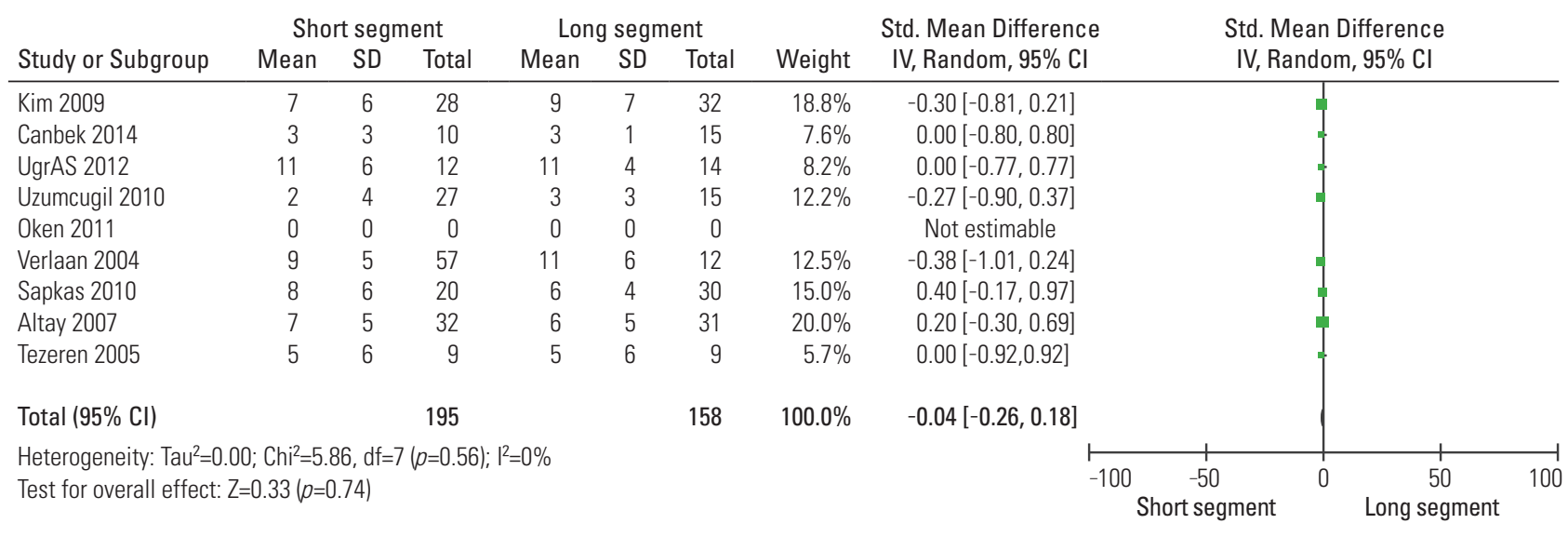

Fig. 4. Forest plot for standardized mean difference postoperative Cobb's angle.

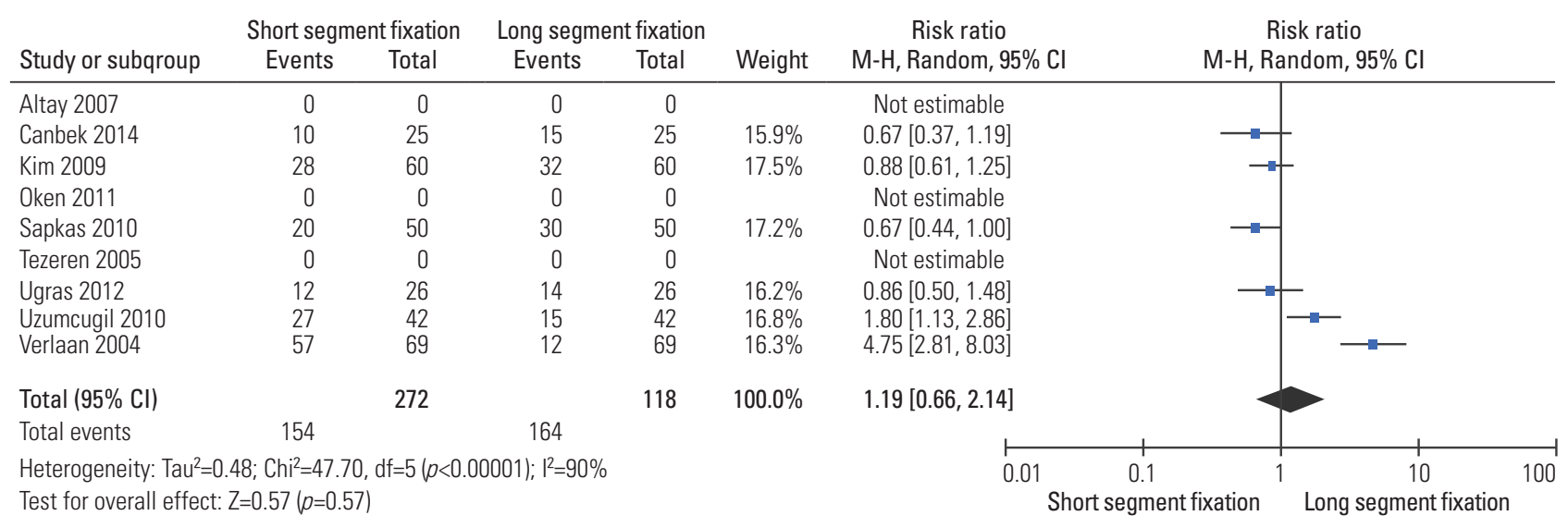

Fig. 5. Risk difference estimate for final follow-up Cobb's angle. 
(3) Sagittal index

The relevant data regarding sagittal index were documented in six articles including 234 patients (short segment group, 118; long segment group, 116) [1,9,13,20,22,23]. The fixed-effects model was applied to determine the difference in sagittal index between the two groups after sensitivity analysis of eliminating the studies of Sapkas et al. [21], Oken et al. [25], and Verlaan et al. [26] (heterogeneity: $\left.I^{2}=44 \%\right)$. The remaining six trials showed that the short segment group had a comparable sagittal index compared to the long segment group. Pooling of relevant data also showed a non significant difference between the two groups (RR, 1.02; 95\% CI, 0.85 to 1.22; $p=0.85$ ) (Figs. $7,8)$.

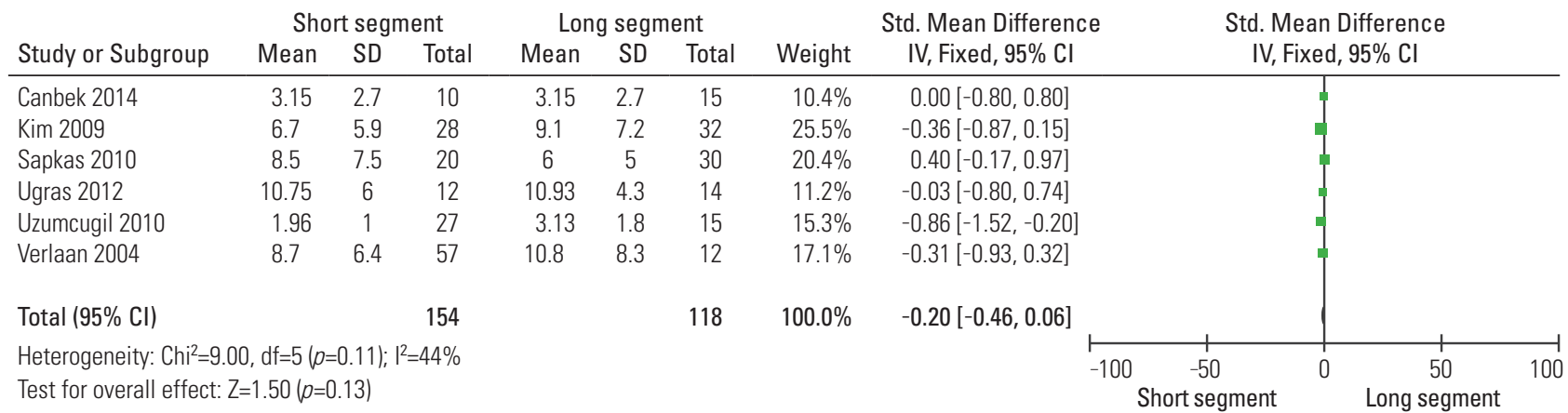

Fig. 6. Standard mean difference estimate for final follow-up Cobb's angle.

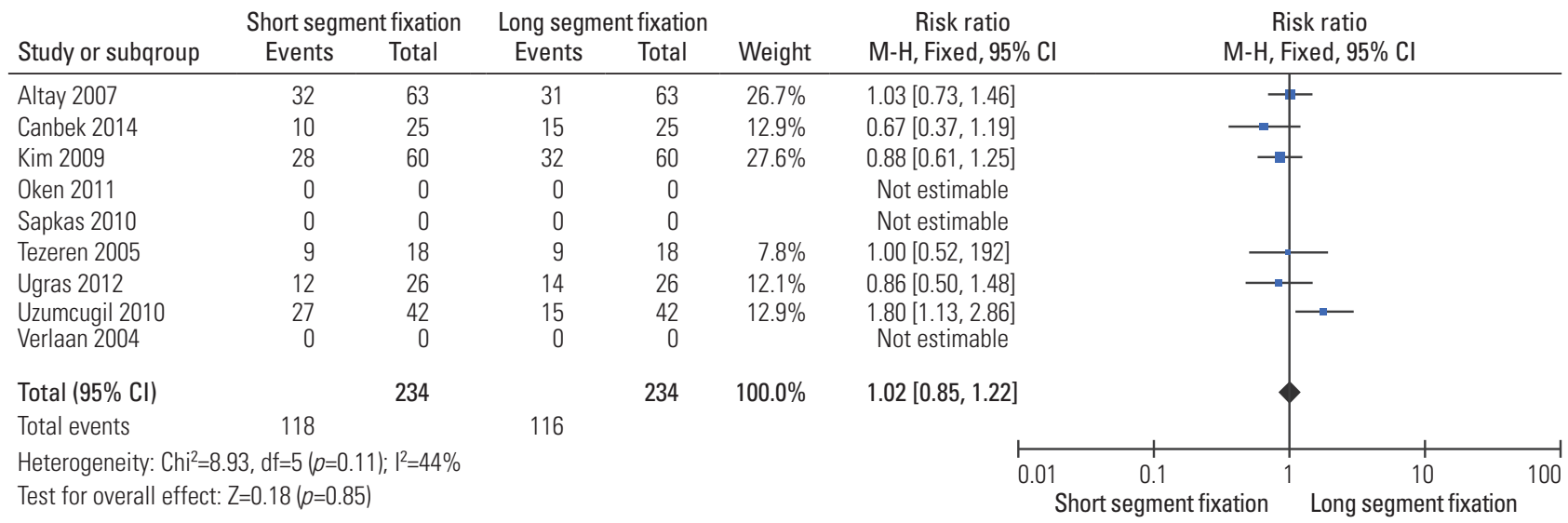

Fig. 7. Risk difference estimate for final follow-up sagittal index.

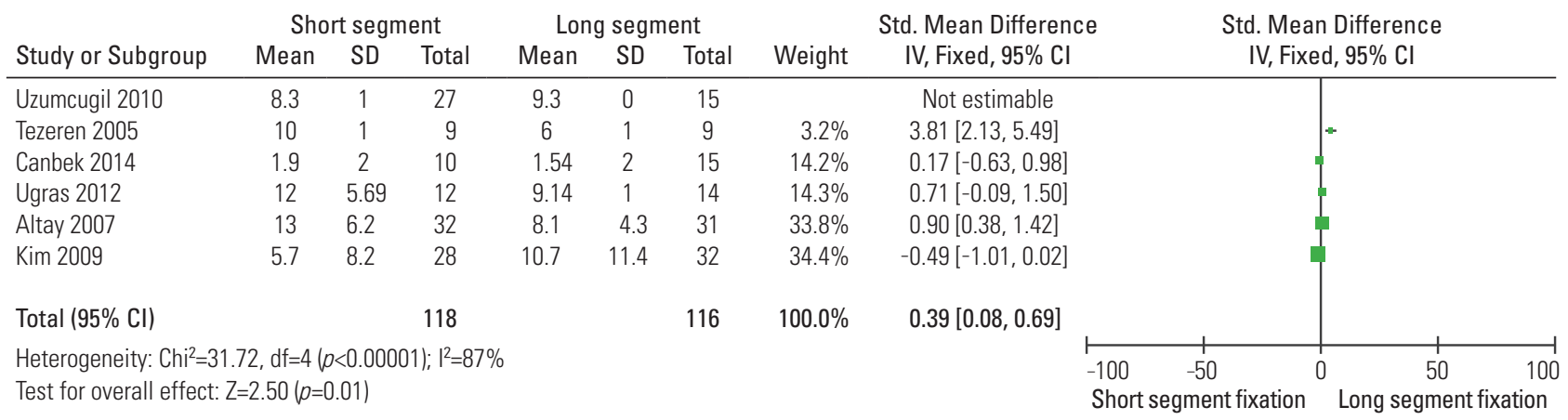

Fig. 8. Standard mean difference estimate at final follow-up for sagittal index in six relevant studies. 


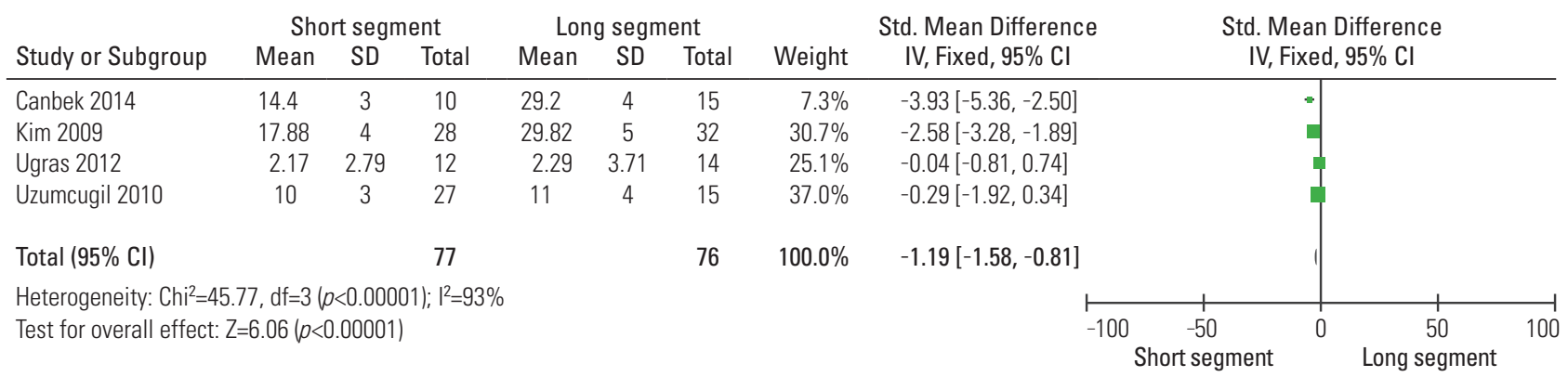

Fig. 9. Standard mean difference estimate at final follow-up for Oswestry disability index in four relevant studies.

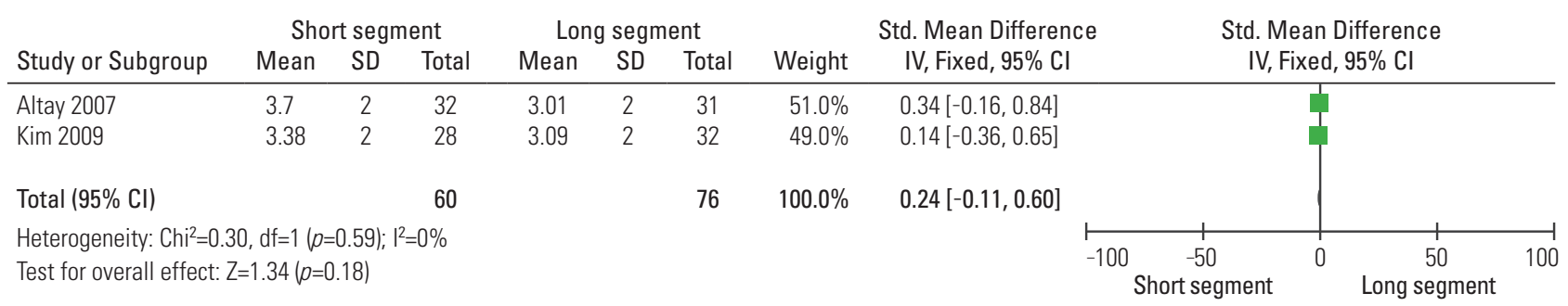

Fig. 10. Standard mean difference estimate at final follow-up for Denis pain scale in two relevant studies.

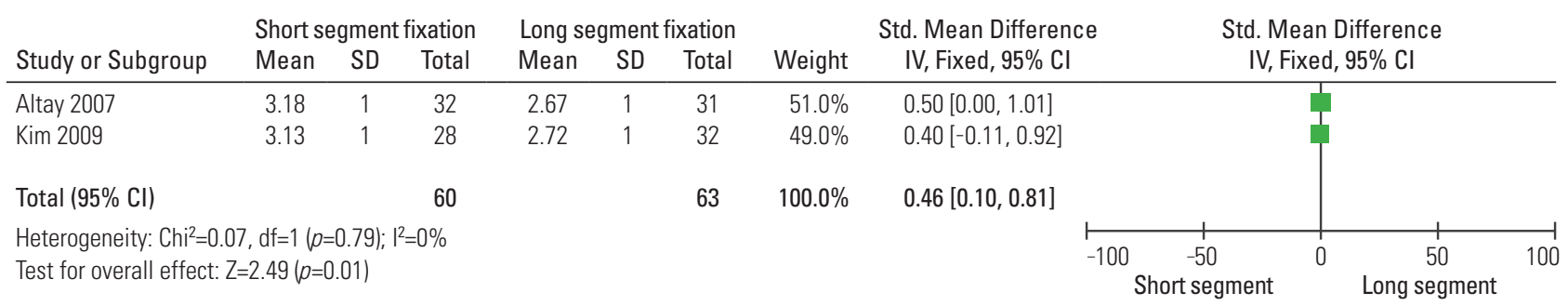

Fig. 11. Standard mean difference estimate at final follow-up for Deniswork scale in two relevant studies.

\section{2) Clinical outcomes}

Five studies [13,20,22,23,26] evaluated neurological and functional recovery. Oswestry disability score was used in 4 studies [1,20,22,23] (Fig. 9), Denis work and pain scales were used in two studies [1,13] (Figs. 10, 11) with total number of 216 patients (109 in short segment fixation group and 92 in long segment fixation group).

The fixed-effects model was applied to compare the preoperative or postoperative clinical scores between the two groups but was accompanied by high heterogeneity $\left(\mathrm{Tau}^{2}=0.94, \mathrm{CHI}^{2}=12.60\right)$. The cause of heterogeneity was investigated by subgroup analysis and sensitivity analysis but could not be ascertained. Finally, a randomeffects model was applied. Pooled data of postoperative disability index did not reveal any significant difference (standardized mean difference, $1.44 ; 95 \%$ CI, 0.66 to 3.15 ; $p=0.36>0.05$ ) and high heterogeneity: $\mathrm{I}^{2}=68 \%$ (Fig. 12). No significant differences were detected between the two groups $(p=0.01)$.

3) Implant failure

The incidence of implant failure was documented in all studies except two $[23,26]$ with a total of 13 patients from 328 patients (10 in short segment group and 3 in long segment group). The fixed-effects model was applied to compare implant failure rate at the end of follow-up between the two groups. The risk ratio of implant-related complications of short segment fixation versus long segment fixation was 0.09 . This comparison showed no significant difference between the two groups $(p=0.52)$ and heterogeneity: $\mathrm{I}^{2}=93 \%, \mathrm{CHI}^{2}=88.40$ (Fig. 13). 


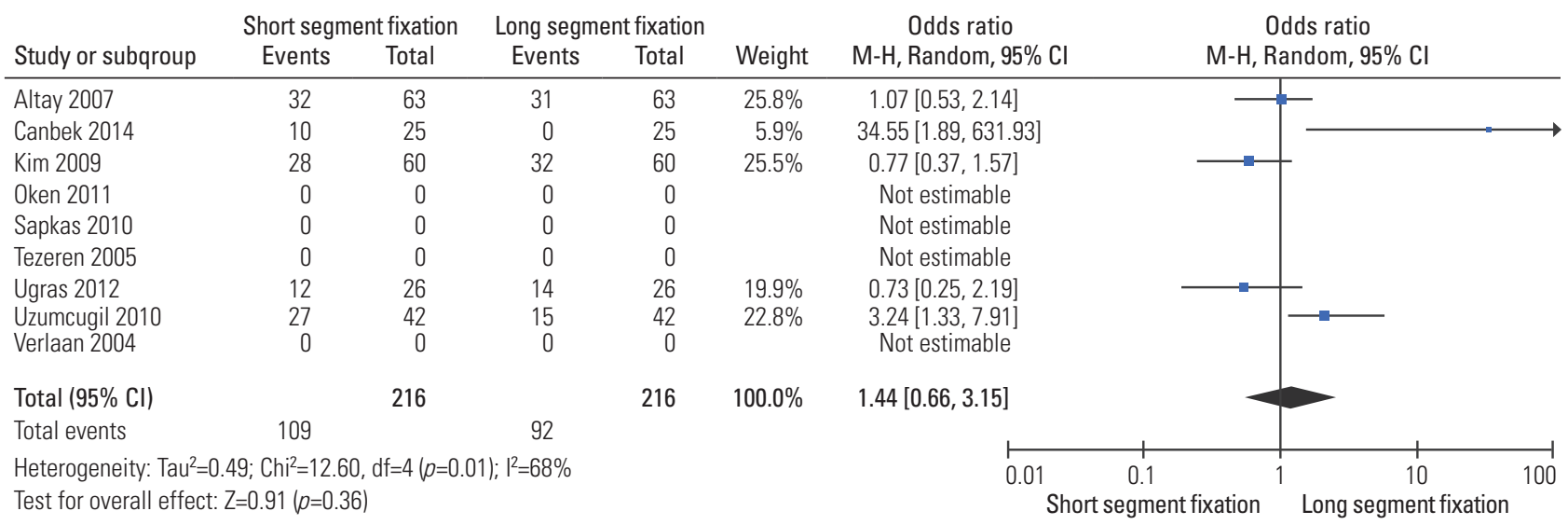

Fig. 12. Odd ratio estimate for final follow-up clinical scores.

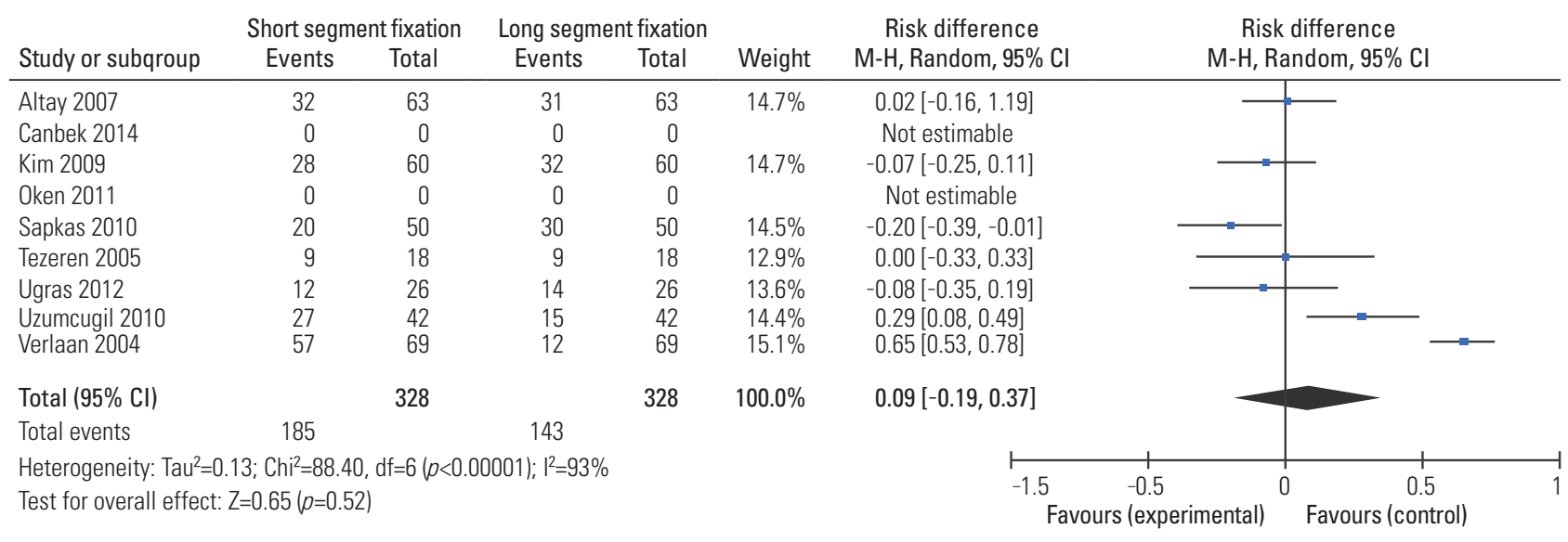

Fig. 13. Risk ratio estimate for implant failure at final follow-up.

\section{Discussion}

Posterior transpedicular screw fixation initially was reported by Boucher [27] in 1959. Since then, modern instrumentation systems have been developed. These systems control segmental motions in three dimensions, preserve motion segments, avoid long fusions, and provide a more stable construct [28]. As with all surgical implants; transpedicular screw instrumentation maintains reduction until bony union is achieved. Short-segment posterior fixation is the most common and simple treatment, offering the advantage of incorporating fewer motion segments in the fusion [7,29-31]. A review of the literature showed that Short-segment posterior fixation alone led to a $9 \%-54 \%$ incidence of implant failure and re-kyphosis in the long-term follow-up, and $50 \%$ of the patients with implant failure had moderate-to-severe pain $[18,29]$. To prevent this, several techniques have been developed to augment the anterior column in burst fractures, such as transpedicular bone grafting [32], polymethyl methacrylate injection, anterior instrumentation and strut grafting, or long-segment posterior fixation $[11,28,33,34]$.

Although short segment pedicle instrumentation has been considered as a superior method, several studies showed that short segment pedicle instrumentation had a high rate of failure. In their report of early failure of short segment pedicle fixation for thoracolumbar burst fracture noted three kinds of hardware failure with this fixation: progressive kyphosis secondary to the bending of screws, kyphosis secondary to osseous collapse or vertebral translation without bending of the hardware, and segmental kyphosis after a caudad screw in the lumbar construct broke. And they noted that untreated anterior instability, and pre-stressing of the screws when the rods 
were contoured in situ, resulted in a high rate of failure $[17,18,35,36]$. Altay et al. [13] reported that use of four pairs of screws (two above and two below) to lengthen the level arm of the construct would probably not only enhance the stability but also allow effective reduction of kyphotic deformity. Short segment posterior fixation alone can give good clinical and radiological outcomes for certain fractures in the thoracolumbar junction. Thus, it is important to detect fractures for which short-segment posterior fixation would be sufficient without leading to implant failure and correction loss and without the need for anterior column support [13]. Tezeren and Kuru [9], in their study comparing short segment versus long segment fixation in thoracolumbar burst fractures, demonstrated that long segment instrumentation is an effective way to manage thoracolumbar burst fractures. Short segment pedicle instrumentation had a high rate of failure. However, long segment instrumentation prolonged the operative time and increased the amount of blood loss significantly. de Peretti et al. [32] suggested that fixation by screw and hook constructs, gripping the two vertebrae above the lesion and screws and hooks gripping the first vertebra below the lesion, was an effective way to stabilize thoracolumbar junction burst fractures. Carl et al. [37] also reported that segmental transpedicular fixation two levels above the kyphosis should be used at the thoracolumbar junction where compressive forces act more anteriorly. Therefore, they prefered to put the pedicle screw two levels above the fracture site in order to prevent progressive kyphosis as well as hard ware failure. On the other hand preferring one level fixation distal to fracture site was to preserve the motion segment as much as possible in the lumbar level. Butt et al. [38], reported success of short segment pedicle screw fixation in thoracolumbar burst fractures; however, the $40 \%$ (20 out of 50 patients) hardware failure rate that they reported is worrisome. Gurr and McAfee [39] found that two-levels above and below the injured level in an unstable calf spine model provided more stiffness than the intact spine. In the present study, hybrid and long posterior fixation significantly improved stability compared to intact and injured conditions in all loading modes. Furthermore, both fixations provided better stability compared to short posterior fixation. Therefore, long posterior fixation appears to be an effective way of managing thoracolumbar burst fractures [39].

Peters et al. [40], in their biomechanical study comparing short segment versus long segment fixation, found that long posterior fixation was the stiffest with and without anterior column augmentation in all loading conditions. The use of screws two above and two below has shown to not only enhance the stability but also allow effective reduction of kyphotic deformity [41]. However, short posterior fixation alone has also shown to provide good clinical and radiological outcomes for certain fractures, particularly in the more lordotic middle and lower lumbar spine, where the compressive forces act more posterior. Katonis et al. [6] found that one-level above and one-level below the fracture in the lumbar area formed a rigid construct with no correction loss.

In this study, we performed meta-analysis comparing patients treated with posterior approach using pedicle screw short segment fixation with those treated with pedicle screw long segment fixation to study the effectiveness of fixation in preventing postoperative development of kyphosis and hardware failure and also for evaluation of clinical improvement. To our knowledge, this is the first quantitative comparative meta-analysis study comparing short and long segment pedicle screw fixation for the treatment of thoracolumbar burst fractures.

The most important purpose of the surgical management of thoracolumbar fractures is to minimize the change in the patients' lives. Pain relief and radiological correction are major outcome criteria for surgical treatment of thoracolumbar burst fractures from the patients' perspective [42]. Denis pain and work scale was used to assess the improvement of back pain in posterior short segment fixation or posterior long segment fixation treated patients during the follow-up periods which ranged from 22 to 71 months [1,23]. Long-term pain relief significantly improved in both treatment groups in all studies. While a major aim of this meta-analysis was to determine which treatment group provided the best long-term pain relief for the treatment of thoracolumbar burst fractures, all studies together indicated that long-term pain relief appeared comparable between the two techniques. Among the included studies, the results showed that there was no significant difference in pain reduction between the two groups.

Our study suggests that although there was no difference in kyphosis between short segment fixation and long segment fixation groups at last follow up, progression of kyphosis occurs in both groups. Xu et al. [43] reported that much of this progression also appears to occur in the initial period after injury.

Although there were ten "events" in the short segment 
fixation group and three events in the long segment fixation group, our results showed that the incidence of implant failure did not differ between the two groups.

We acknowledge some limitations of the literature and our review. First, although several relevant trials have been published, the majority were small and of low quality. Few comparative trials satisfied our inclusion criteria, including nine articles. As a result, we could not perform subgroup analysis because the information required was unavailable. We could not perform subgroup analysis based on burst fracture type as the information required was unavailable in almost all included studies. Second, the heterogeneity of the study populations in terms of complications and therapeutic options posed additional challenges in evaluating the individual therapeutic options. This clinical heterogeneity, combined with the small sample sizes of the included studies, resulted in high $\mathrm{I}^{2}$ values for our pooled results for pain scale, Cobb angle and implant failure. Third, the use of variable outcome measures and suboptimal reporting, often at nonstandardized intervals, further undermined informed decision-making. Lastly, we must mention that the selection of the surgical approach for the treatment of thoracolumbar fractures should be individualized because many factors influence this choice. Despite these reservations, our review incorporates an individual patient data meta-analysis of studies comparing posterior short segment pedicle screws fixation and long segment pedicle screws fixation management of patients with thoracolumbar burst fractures, and we believe reflects the best evidence currently available. As such, this review hopefully will facilitate greater evidencebased practice and quality management.

\section{Conclusions}

The results of this meta-analysis showed that in the surgical management of thoracolumbar burst fractures through posterior approach, the short segment pedicle screws fixation was not significantly different to the long segment pedicle screws fixation in terms of improvement of back pain and return to work and also in correction of kyphotic deformity.

\section{Conflict of Interest}

No potential conflict of interest relevant to this article was reported.

\section{Acknowledgments}

The author would like to thank AOSpine middle east for their education, support and continuous training.

\section{References}

1. Kim GW, Jang JW, Hur H, Lee JK, Kim JH, Kim SH. Predictive factors for a kyphosis recurrence following short-segment pedicle screw fixation including fractured vertebral body in unstable thoracolumbar burst fractures. J Korean Neurosurg Soc 2014;56:230-6.

2. Dai LY, Yao WF, Cui YM, Zhou Q. Thoracolumbar fractures in patients with multiple injuries: diagnosis and treatment-a review of 147 cases. J Trauma 2004; 56:348-55.

3. Denis F. The three column spine and its significance in the classification of acute thoracolumbar spinal injuries. Spine (Phila Pa 1976) 1983;8:817-31.

4. Jacobs RR, Asher MA, Snider RK. Thoracolumbar spinal injuries: a comparative study of recumbent and operative treatment in 100 patients. Spine (Phila Pa 1976) 1980;5:463-77.

5. Kaneda K, Taneichi H, Abumi K, Hashimoto T, Satoh S, Fujiya M. Anterior decompression and stabilization with the Kaneda device for thoracolumbar burst fractures associated with neurological deficits. J Bone Joint Surg Am 1997;79:69-83.

6. Katonis PG, Kontakis GM, Loupasis GA, Aligizakis AC, Christoforakis JI, Velivassakis EG. Treatment of unstable thoracolumbar and lumbar spine injuries using Cotrel-Dubousset instrumentation. Spine (Phila Pa 1976) 1999;24:2352-7.

7. Parker JW, Lane JR, Karaikovic EE, Gaines RW. Successful short-segment instrumentation and fusion for thoracolumbar spine fractures: a consecutive 41/2year series. Spine (Phila Pa 1976) 2000;25:1157-70.

8. Sasso RC, Best NM, Reilly TM, McGuire RA Jr. Anterior-only stabilization of three-column thoracolumbar injuries. J Spinal Disord Tech 2005;18 Suppl:S7-14.

9. Tezeren G, Kuru I. Posterior fixation of thoracolumbar burst fracture: short-segment pedicle fixation versus long-segment instrumentation. J Spinal Disord Tech 2005;18:485-8.

10. Chen HH, Wang WK, Li KC, Chen TH. Biomechanical effects of the body augmenter for reconstruction 
of the vertebral body. Spine (Phila Pa 1976) 2004;29: E382-7.

11. Dai LY, Jiang LS, Jiang SD. Anterior-only stabilization using plating with bone structural autograft versus titanium mesh cages for two- or three-column thoracolumbar burst fractures: a prospective randomized study. Spine (Phila Pa 1976) 2009;34:1429-35.

12. Modi HN, Chung KJ, Seo IW, et al. Two levels above and one level below pedicle screw fixation for the treatment of unstable thoracolumbar fracture with partial or intact neurology. J Orthop Surg Res 2009; $4: 28$.

13. Altay M, Ozkurt B, Aktekin CN, Ozturk AM, Dogan O, Tabak AY. Treatment of unstable thoracolumbar junction burst fractures with short- or long-segment posterior fixation in magerl type a fractures. Eur Spine J 2007;16:1145-55.

14. Guven O, Kocaoglu B, Bezer M, Aydin N, Nalbantoglu U. The use of screw at the fracture level in the treatment of thoracolumbar burst fractures. J Spinal Disord Tech 2009;22:417-21.

15. Mahar A, Kim C, Wedemeyer M, et al. Short-segment fixation of lumbar burst fractures using pedicle fixation at the level of the fracture. Spine (Phila $\mathrm{Pa}$ 1976) 2007;32:1503-7.

16. Tezeren G, Gumus C, Bulut O, Tukenmez M, Oztemur Z, Sever G. Anterior versus modified combined instrumentation for burst fractures of the thoracolumbar spine: a biomechanical study in calves. J Orthop Surg (Hong Kong) 2008;16:281-4.

17. McLain RF, Sparling E, Benson DR. Early failure of short-segment pedicle instrumentation for thoracolumbar fractures: a preliminary report. J Bone Joint Surg Am 1993;75:162-7.

18. Alanay A, Acaroglu E, Yazici M, Oznur A, Surat A. Short-segment pedicle instrumentation of thoracolumbar burst fractures: does transpedicular intracorporeal grafting prevent early failure? Spine (Phila Pa 1976) 2001;26:213-7.

19. Kim HS, Lee SY, Nanda A, et al. Comparison of surgical outcomes in thoracolumbar fractures operated with posterior constructs having varying fixation length with selective anterior fusion. Yonsei Med J 2009;50:546-54.

20. Uzumcugil O, Dogan A, Yetis M, Yalcinkaya M, Caniklioglu M. Results of 'two above: one below approach' with intermediate screws at the fracture site in the surgical treatment of thoracolumbar burst fractures. Kobe J Med Sci 2010;56:E67-78.

21. Sapkas G, Kateros K, Papadakis SA, Brilakis E, Macheras G, Katonis P. Treatment of unstable thoracolumbar burst fractures by indirect reduction and posterior stabilization: short-segment versus longsegment stabilization. Open Orthop J 2010;4:7-13.

22. Ugras AA, Akyildiz MF, Yilmaz M, Sungur I, Cetinus E. Is it possible to save one lumbar segment in the treatment of thoracolumbar fractures? Acta Orthop Belg 2012;78:87-93.

23. Canbek U, Karapinar L, Imerci A, Akgun U, Kumbaraci $M$, Incesu $M$. Posterior fixation of thoracolumbar burst fractures: is it possible to protect one segment in the lumbar region? Eur J Orthop Surg Traumatol 2014;24:459-65.

24. Jorgensen L, Paludan-Muller AS, Laursen DR, et al. Evaluation of the Cochrane tool for assessing risk of bias in randomized clinical trials: overview of published comments and analysis of user practice in Cochrane and non-Cochrane reviews. Syst Rev 2016; 5:80.

25. Oken F, Yildirim O, Oken O, Gulcek M, Yavuzer G, Ucaner A. Short or long fusion after thoracolumbar burst fractures does not alter selected gait parameters: a preliminary study. J Orthop Res 2011;29:9158.

26. Verlaan JJ, Diekerhof CH, Buskens E, et al. Surgical treatment of traumatic fractures of the thoracic and lumbar spine: a systematic review of the literature on techniques, complications, and outcome. Spine (Phila Pa 1976) 2004;29:803-14.

27. Boucher HH. A method of spinal fusion. J Bone Joint Surg Br 1959;41:248-59.

28. Roy-Camille R, Saillant G, Mazel C. Internal fixation of the lumbar spine with pedicle screw plating. Clin Orthop Relat Res 1986;(203):7-17.

29. Akbarnia BA, Crandall DG, Burkus K, Matthews T. Use of long rods and a short arthrodesis for burst fractures of the thoracolumbar spine: a long-term follow-up study. J Bone Joint Surg Am 1994;76:162935.

30. Knop C, Bastian L, Lange U, Oeser M, Zdichavsky M, Blauth M. Complications in surgical treatment of thoracolumbar injuries. Eur Spine J 2002;11:214-26.

31. Li KC, Hsieh CH, Lee CY, Chen TH. Transpedicle body augmenter: a further step in treating burst frac- 
tures. Clin Orthop Relat Res 2005;(436):119-25.

32. de Peretti F, Hovorka I, Cambas PM, Nasr JM, Argenson C. Short device fixation and early mobilization for burst fractures of the thoracolumbar junction. Eur Spine J 1996;5:112-20.

33. Kuner EH, Kuner A, Schlickewei W, Mullaji AB. Ligamentotaxis with an internal spinal fixator for thoracolumbar fractures. J Bone Joint Surg Br 1994;76:10712.

34. Cho DY, Lee WY, Sheu PC. Treatment of thoracolumbar burst fractures with polymethyl methacrylate vertebroplasty and short-segment pedicle screw fixation. Neurosurgery 2003;53:1354-60.

35. Dick W, Kluger P, Magerl F, Woersdorfer O, Zach G. A new device for internal fixation of thoracolumbar and lumbar spine fractures: the 'fixateur interne'. Paraplegia 1985;23:225-32.

36. Rommens PM, Weyns F, Van Calenbergh F, Goffin J, Broos PL. Mechanical performance of the Dick internal fixator: a clinical study of 75 patients. Eur Spine J 1995;4:104-9.

37. Carl AL, Tromanhauser SG, Roger DJ. Pedicle screw instrumentation for thoracolumbar burst fractures and fracture-dislocations. Spine (Phila Pa 1976)
1992;17(8 Suppl):S317-24.

38. Butt MF, Farooq M, Mir B, Dhar AS, Hussain A, Mumtaz M. Management of unstable thoracolumbar spinal injuries by posterior short segment spinal fixation. Int Orthop 2007;31:259-64.

39. Gurr KR, McAfee PC. Cotrel-Dubousset instrumentation in adults. A preliminary report. Spine (Phila Pa 1976) 1988;13:510-20.

40. Peters T, Chinthakunta SR, Hussain M, Khalil S. Pedicle screw configuration for thoracolumbar burst fracture treatment: short versus long posterior fixation constructs with and without anterior column augmentation. Asian Spine J 2014;8:35-43.

41. Lazaro BC, Deniz FE, Brasiliense LB, et al. Biomechanics of thoracic short versus long fixation after 3-column injury. J Neurosurg Spine 2011;14:226-34.

42. Reid DC, Hu R, Davis LA, Saboe LA. The nonoperative treatment of burst fractures of the thoracolumbar junction. J Trauma 1988;28:1188-94.

43. Xu GJ, Li ZJ, Ma JX, Zhang T, Fu X, Ma XL. Anterior versus posterior approach for treatment of thoracolumbar burst fractures: a meta-analysis. Eur Spine J 2013;22:2176-83. 